\title{
Subclinical Infection of the Genital Tract With Neisseria meningitidis
}

\author{
Maria Cristina S. Lourenço ${ }^{1}$, \\ Roberto S. Reis ${ }^{1}$, Angela C. V. Andrade ${ }^{2}$, \\ Mari Tuyama ${ }^{3}$ and David E Barroso ${ }^{3}$
}

\author{
${ }^{1}$ Bacteriology and ${ }^{2}$ Gynaecology sections, Evandro Chagas Research \\ Institute, FIOCRUZ; ${ }^{3}$ Department of Bacteriology, Oswaldo Cruz Institute, \\ FIOCRUZ; Rio de Janeiro, RJ, Brazil
}

\begin{abstract}
We report the isolation of Neisseria meningitidis, characterized as B:NT:P1.7, from a female patient's genital tract in an outpatient clinic for HIV care. The gynecology clinic, as part of the follow up, collects specimens from all patients with HIV infection for routine exams and for early laboratory detection of sexually transmitted diseases . A Gram-negative diplococcus was isolated from the cervix of a heterosexual patient with AIDS. Based on this and other reported cases, urogenital infection with $N$. meningitidis can no longer be considered uncommon. The rising incidence of $N$. meningitidis isolated from this and similar sites has significant medical and diagnostic implications.

Key Words: Neisseria meningitidis, genital infection, AIDS.
\end{abstract}

Neisseria meningitidis is a normal commensal of human mucous membranes that is no longer considered to be restricted to the nasopharynx, although this is the most frequent site identified as its reservoir [1,2-4]. Colonization of mucous membranes normally results in subclinical infection, since progression to host invasion or focal disease is a relatively rare event. A carrier ratio of $5 \%$ to $10 \%$ is estimated in the general population, which can reach $30 \%-90 \%$ in close contact of cases. Transmission occurs through direct contact with large droplet respiratory secretions from asymptomatic carriers or, infrequently, from patients [4]. Sometimes the organism can be found in unusual sites, such as the mucous membranes of the endocervix, urethra or anus [2]. Due to the practice of oral sex, these membranes have become an important potential infection site for respiratory bacteria. We report here the isolation of $N$. meningitidis from the endocervix of a heterosexual female, first diagnosed presumptively as Neisseria gonorrhoeae, but later identified as $N$. meningitidis.

\section{Case Report}

A 65-year-old woman with Chagas disease and AIDS presented at the gynecology clinic for routine follow up. Her genital exam was normal. The mucous from the cervix was collected and spread onto chocolate (heated blood) agar and Thayer-Martin medium plates, as a regular procedure of the clinic. After $48 \mathrm{~h}$ of incubation, growth of non-pigmented transparent colonies was observed on the culture plates. The colonies were oxidase-positive, with the appearance of Gramnegative diplococci. A culture was sent to the FIOCRUZ Bacteriology Department for confirmatory identification.

Received on 04 January 2006; revised 18 March 2006.

Address for correspondence: Dr. David E. Barroso, Departamento de Bacteriologia, Instituto Oswaldo Cruz, FIOCRUZ, Pavilhão Rocha Lima, $3^{\circ}$ andar, Av. Brasil 4365, Rio de Janeiro, R.J. 21040-900, Brasil; E-mail: barroso@ioc.fiocruz.br. PhonelFax: 55.21.2270-1599

The Brazilian Journal of Infectious Diseases 2006;10(2):154-155. (C) 2006 by The Brazilian Journal of Infectious Diseases and Contexto Publishing. All rights reserved.
The chocolate agar plate that was received had a pure culture and was subcultured on both chocolate agar and Müller-Hinton agar, without supplements; it was incubated $24 \mathrm{~h}$ in $5 \% \mathrm{CO}_{2}$ atmosphere. The isolate was characterized as Gram-negative diplococcus, non-beta-lactamase-producing, and positive for oxidase and catalase reactions. The bacterium was identified, with the api NH system (bioMérieux), as $N$. meningitidis. The phenotype B:NT:P1.7 was determined by means of slide agglutination with specific antiserum (Difco) and with a dot-blotting assay with monoclonal antibody (National Meningitis Reference Center, Instituto Adolfo Lutz). The E-test (AB BIODISK) for testing susceptibility of the organism did not show resistance to penicillin, chloramphenicol, ceftriaxone, rifampicin, ciprofloxacin, or sulfadiazine. There was evidence of cervicitis in the histopathological analysis. The patient was treated with a single dose of ceftriaxone ( $250 \mathrm{mg}$ intramuscularly); a follow up culture was negative. No throat swab specimen was available from this patient, nor were urethral or throat specimens obtained from her sexual partner. Appropriate chemoprophylaxis was not prescribed to close contacts.

\section{Discussion}

Neisseria meningitidis infections of the urogenital tract were considered rare until recently; but during the past few decades an increasing number of cases of genital tract infections or colonization have been reported, usually due to serogroups B, C or Y [3-6]. Correct identification of $N$. meningitidis in the genital tract can be difficult because of the existence of maltose-negative strains, which can be erroneously diagnosed as $N$. gonorrhoeae [7]. Indeed, the identification of Neisseria species can be no longer presumed on the basis of the site of infection. Thus a definite identification, with the use of biochemical tests, immunological methods, and molecular assays, is necessary $[1,2,8]$.

The increase in the frequency of $N$. meningitidis infection has not been influenced by the advent of AIDS [5,9]. The most likely route of transmission of urogenital infection caused by $N$. meningitidis seems to be orogenital contact with a sexual 
partner carrying the microorganism in the nasopharynx $[6,10]$. Sexual activities play a role in the spread and infection of other body sites with respiratory bacteria from close contact between partners in a domestic context [10,11]. Anogenital infection with this bacterium can be either asymptomatic or with clinical evidence of disease [5]. This disruption in the ecological isolation with $N$. gonorrhoeae could provoke modifications in the gene structure of both species [12].

\section{Acknowledgements}

We appreciate the assistance of Dr. Ana Paula de Lemos, who did the sero-subtyping (Instituto Adolfo Lutz, São Paulo, Brazil).

\section{References}

1. Olcén P., Danielsson D., Kjellander J. Laboratory identification of pathogenic Neisseria with special regard to atypical strains: an evaluation of sugar degradation, immunofluorescence and co-agglutination tests. APMIS 1978;36(sec. B):327-34.

2. Martin P., Guibourdenche M., Riou J.Y. A propos des Neisseria et Branhamella trouvées em localisation inhabituelle. Ann Biol Clin 1981;39:273-8.

3. Hagman M., Forslin L., Moi H., Danielsson D. Neisseria meningitidis in specimens from urogenital sites. Is increased awareness necessary? Sex Transm Dis 1991;18:228-32.
4. Morello J.A., Janda W.M., Doern G.V. Neisseria and Branhamella. In Balows A, Hansler WJ jr, Herrmann KL, Isenberg HD, Shadomy HJ, Manual of Clinical Microbiology, ASM, Washington, 1991:258-76.

5. McKenna J.G., Fallon R.J., Moyes A., Young H. Anogenital non-gonococcal neisseriae: prevalence and clinical significance. Int J STD AIDS 1993;4: 8-12.

6. Urra E., Alkorta M., Sota M., et al. Orogenital transmission of Neisseria meningitidis serogroup C confirmed by genotyping techniques. Eur J Clin Microbiol Infect Dis 2005;24:51-3.

7. Phillips E.A., Tifffany R.S., Tapsall J.W., Chambres I.W. Maltose-negative Neisseria meningitidis isolated from a case of male urethritis. J Clin Microbiol 1989;37:2851-2.

8. Porrit R.J., Mercer J.L., Munro R. Detection and serogroup determination of Neisseria meningitidis in CSF by polymerase chain reaction (PCR). Pathol 2000;32:42-5.

9. Morla N., Guibourdenche M., Riou J.-Y. Neisseria spp. and AIDS. J Clin Microbiol 1992;30:2290-4.

10. Harriau P., Ramanantsoa C., Pierre F., et al. Endocervical infection in a pregnant woman caused by Neisseria meningitidis: evidence of associated oropharyngeal colonization of the male partner. Euro J Obstet Gyn Reproduct Biol 1997;74:145-7.

11. Edwards S., Carne C. Oral sex and transmission of non-viral STIs. Sex Transm Inf 1998;74:95-100.

12. Ameyama S., Onodera S., Takahata M., et al. Mosaic-Like Structure of Penicillin-Binding Protein 2 Gene (penA) in Clinical Isolates of Neisseria gonorrhoeae with Reduced Susceptibility to Cefixime. Antimicrob Agents Chemother 2002;46:3744-9. 